\title{
A LeI da Liberdade EConômica e os novos paradigmas DA INTERVENÇÃO DO ESTADO NO DOMÍNIO ECONÔMICO
}

\author{
THE LAW OF ECONOMIC FREEDOM AND THE NEW PARADIGMS \\ OF STATE INTERVENTION IN THE ECONOMIC FIELD
}

Acesse o QR Code para visualizar este artigo em Visual Law

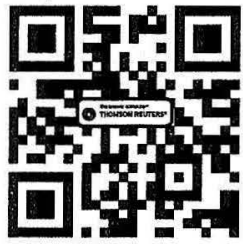

Vinícius Périssé Maia Veras

Graduando em Direito (UERJ). ORCID: [https://orcid.org/0000-0001-9597-7946]. viniciuspmveras@gmail.com

\section{Valter Shuenouener de Araujo}

Professor-Associado de Direito Administrativo da Faculdade de Direito da UERJ. Doutor em Direito Público (UERJ). Secretário-Geral do CNJ. Juiz federal. ORCID: [https://orcid.org/0000-0003-1584-5340]. vsaraujo19@gmail.com

Recebido em: 27.09 .2020

Aprovado em: 16.10 .2020

\section{ÁreA do DiReITo: Financeiro e Econômico}

RESUMO: 0 presente artigo estuda as principais mudanças introduzidas pela Lei 13.874/2019. A recente história econômica brasileira é marcada por forte intervenção do Estado na economia, seja de forma direta, seja indireta. Com o advento da Constituição da República de 1988, foi instaurado um novo modelo de ordem econômica centralizado na livre-iniciativa. Entretanto, é possível constatar, por meio de estudos estatísticos e pesquisa da jurisprudência, que tal modelo não fora posto em prática, mantendo-se a forte tradição estatizante do Pais. Com a Lei da Liberdade Econômica, nota-se um movimento normativo com capacidade de alterar essa realidade. Por fim, chegou-se à conclusão de que

\begin{abstract}
This article studies the main changes brought by Law 13,874 of September 20, 2019. The recent Brazilian economic history is marked by strong state intervention in the economy, either directly or indirectly. With the advent of the Republic Constitution of 1988, a new model of economic order based on free enterprise was introduced. However, it was possible to verify, with the various statistical studies, as well as the research of the jurisprudence that such model was not put into practice, maintaining the strong statist tradition of the country. With the enactment of the so-called Economic Freedom Law, we can notice a legal movement capable of changing this reality. Finally, it was concluded
\end{abstract}


a Lei $13.874 / 2019$ possui um grande potencial transformador, capaz de criar paradigmas e limites para a intervenção estatal na economia, desde que bem regulada e interpretada conforme os fins ditados pela Constituição.

Palavras-chave: Lei 13.874/2019 - Liberdade econômica - Intervenção do Estado no dominio econômico - Livre-iniciativa - Ordem econômica. that Law $13,874 / 2019$ has great transformative potential, capable of creating new paradigms and limits for state intervention in the economy, provided that it is well regulated and interpreted according to the purposes dictated by the Constitution.

KeYwords: Law 13,874/2019 - Economic freedom - State intervention in the economic field Free initiative - Economic order.

SumÁRı: 1. Introdução. 2. A dimensão jurídica da liberdade econômica: o princípio da livre-iniciativa e os limites tradicionais à intervenção do Estado no domínio econômico. 3. A livre-iniciativa na jurisprudência do Supremo Tribunal Federal: a confirmação de um diagnóstico antiliberal. 4. A Lei da Liberdade Econômica: os novos limites à intervenção do Estado no domínio econômico e o abuso do poder regulatório. 5. Uma interpretação pró-particular: os efeitos positivos do silêncio administrativo como garantia da livre-iniciativa. 6. Em busca de uma regulação mais democrática: a análise de impacto regulatório na Lei da Liberdade Econômica. 7. Conclusão. 8. Referências.

\section{INTRODUÇÃO}

O Brasil figura na $150^{a}$ posição mundial no Índice de Liberdade Econômica de $2019^{1}$ publicado pela Heritage Foundation. Tal desempenho denota que, nem na atualidade nem ao longo da história recente do País, valores como a livre-iniciativa e a livre concorrência lograram atingir um protagonismo na sociedade e no ordenamento jurídico, a despeito de sua positivação expressa na Constituição de 1988.

Em 2019, a pauta econômica marcou presença no debate popular com muita força. Grandes discussões sobre Reforma da Previdência, Reforma Tributária e Reforma Administrativa tomaram os noticiários e as redes sociais. Nesse contexto, de grande efervescência-e, também, de grande polarização política - que foi editada a Medida Provisória 881/2019, depois convertida na Lei 13.874, de 20 de setembro de 2019.

Conforme será demonstrado, além do impacto singular de cada nova norma, a Lei 13.874/2019 tem o potencial para representar uma verdadeira "virada de jogo" no Direito Público, instaurando um novo paradigma interpretativo acerca da intervenção do Estado no Domínio Econômico. Nas últimas décadas, a concretização dos fins sociais previstos na Constituição da República passou a ser sinônimo de abandonar a livre-iniciativa, que teria de ceder diante de razões consideradas caras ao interesse público. Ocorre que tal método contraria o texto constitucional, que estabelece a livre-iniciativa como

1. HERITAGE FOUNDATION. 2019 Index of Economic Freedom. Disponivel em: [www.heritage.org/ index/ranking]. Acesso em: 03.09.2019.

Veras, Vinicius Périssé Maia; Araujo, Valter Shuenquener de. A Lei da Liberdade Econômica e os novos paradigmas da intervenção do Estado. Revista de Direito Administrativo, Infraestrutura, Regulação e Compliance. 